\title{
Experimental study and thermodynamic modelling of ethylene absorption in N-methyl-2-pyrrolidone (NMP)
}

\author{
Mohammad Yousefi $^{1}$-Shima Azizi ${ }^{1}$ - S. M. Peyghambarzadeh ${ }^{1} \cdot$ Zoha Azizi $^{1}$
}

Received: 5 May 2020 / Accepted: 3 July 2020 / Published online: 13 July 2020

(c) The Author(s) 2020

\begin{abstract}
Determining the solubility of gases in solvents and considering non-idealities at different operating conditions are essential to design a cost-effective and energy-efficient absorption process. In this work, using a lab-made set-up, solubility of ethylene in N-methyl-2-pyrrolidone (NMP) was measured at different temperatures $(278.15,298.15$, and $328.15 \mathrm{~K})$ and pressures up to 14 bar, and the kinetic and equilibrium data were obtained. Accordingly, Henry's law constants are calculated at various temperatures. Then, thermodynamic modeling was accomplished by applying Peng-Robinson equation of state (PR-EOS) and Wilson activity coefficient model, and the binary interaction parameters were estimated. By the thermodynamic modeling, positive deviation from ideal behavior was apparently observed. Due to low absolute average deviation of $<7.7 \%$, the correlated model was able to predict the ethylene solubility in NMP with a reliable accuracy.
\end{abstract}

Keywords Ethylene $\cdot \mathrm{N}$-methyl-2-pyrrolidone $(\mathrm{NMP}) \cdot$ Solubility $\cdot$ Peng Robinson $\cdot$ Wilson $\cdot$ Thermodynamic modeling

\section{Abbreviations}

\section{Nomenclature}

AAD Absolute Average Deviation (dimensionless)

E Activity Energy $\left(\frac{k J}{m o l}\right)$

$\mathrm{H}$ Henry's Law Constant (bar)

Mw Molecular Weight $\left(\frac{g}{m o l}\right)$

n Moles (dimensionless)

P Pressure (bar)

R Gas Constant $\left(\frac{\mathrm{cm}^{3} \cdot b a r}{\mathrm{~mol} \cdot \mathrm{K}}\right)$

$\mathrm{T} \quad$ Temperature $(\mathrm{K})$

$\mathrm{V} \quad$ Volume (ml)

$\mathrm{x} \quad$ Solubility or Mole Fraction in Liquid Phase (dimensionless)

y Mole Fraction in Gas Phase (dimensionless)

$\mathrm{Z} \quad$ Compressibility Factor (dimensionless)

\section{Greek letter}

$\omega \quad$ Acentric Factor (dimensionless)

$\rho \quad$ Density $\left(\frac{g}{\mathrm{~cm}^{3}}\right)$

$\Phi \quad$ Fugacity Coefficient (dimensionless)

S. M. Peyghambarzadeh

peyghambarzadeh@gmail.com

1 Department of Chemical Engineering, Mahshahr Branch, Islamic Azad University, Mahshahr, Iran $\gamma: \quad$ Activity Coefficient (dimensionless)

$\Lambda \quad$ Binary Interaction Parameters of Wilson equation (dimensionless)

\section{Subscripts and superscripts}

1 Initial

c Critical

exp Experimental

eq Equilibrium

f Final

g Gas

i Component i

j Component $\mathrm{j}$

mod Model

r Reduced

S Solvent

sat Saturation

t Total

\section{Introduction}

Ethylene is one of important petrochemical feed stocks which is utilized as the main feed of polyethylene, polyethylene oxide, polyethylene glycol, and ethanol production plants $[10,18,22,31]$. Design aspects and high productivity of the aforementioned plants require that the utilized ethylene be of a great purity of more than $99.9 \%[25,35]$. 
The cryogenic distillation which consumes $20 \%$ of the total required energy of a cracking plant [35], is the most widely used method to separate ethylene from ethane and produced the on-spec ethylene for downstream plants. However, severe operating conditions and expensive distillation facilities cause the new proposed methods to be encouraged $[1,37]$. Other methods such as extractive distillation, adsorption, and membrane separation technologies have their own constraints such as higher operating cost, complicated technology, and high energy consumption $[1,2,16$, $25,35]$. These problems caused these technologies have not been used in industries yet.

Absorption is another ethylene purification method in which a proper selective solvent should be applied to separate ethylene from its containing mixture. Various solvents were proposed for ethylene absorption in the literature. Polyethylene [7], ionic liquids [19, 20], methylpropionate [30], toluene [17, 28], norbornene [28], CuCl/Aniline/Nmethylpyrrolidone [25], aqueous silver nitrate [8] are some examples.

Despite the selectivity and efficiency of these solvents, due to relatively high vapor pressures relative to water as a solvent, they required an additional step to remove water [1]. Also, an increase in temperature or the presence of a sweep gas in the stripping step will cause a large amount of solvent to evaporate [19]. Hence, the use of a solvent with less vapor pressure may reduce the anxiety cause by drying of olefins. One solvent that provided this property for the process was NMP solvent or a mixture of this solvent with other solvents, including alcohols [6]. On the other hand, the reasonable price of NMP was another reason for choosing it.

In addition to experimental studies, thermodynamic modeling is also studied for gas absorption and solubility. The purpose of these modeling is to find the solubility of gases in a wide range of temperatures and pressures. One of the reason of modeling is to find optimal parameters of the thermodynamic models [1]. For example, Wu et al. [38] measured the solubility of carbon dioxide, ethane and ethylene gases in NMP and a mixture of water and NMP at $298 \mathrm{~K}$ in a low pressure set-up at atmospheric pressure. With these results, they were able to find the Henry's constants and Ostwald coefficients as a function of solute-free solvent composition.

Henni et al. [12] measured ethane solubility in NMP solvent at $263-393 \mathrm{~K}$ and pressure up to $71 \mathrm{bar}$ and compared the results with other physical solvents. These results were correlated with the PR-EOS and the binary interaction parameters were obtained. Also, Henry's law constants were determined.

Dojčanský and J-Surový [9] measured the P-x data for mixtures hexane/cyclohexane, hexane/benzene/cyclohexane, hexane/cyclohexane/N-methylpyrrolidone, and hexane/benzene/N-methylpyrrolidone at $343 \mathrm{~K}$. These equilibrium data were then used to predict the binary interaction coefficients of the Wilson equation for these multicomponent mixtures in the extractive distillation.

Lee et al. [17] investigated the solubility of ethylene in toluene solvent at a temperature range of 323-423 K, and pressure of 5-25 bars with a pressure decaying method. By applying the experimental solubility results, the binary interaction parameters of PR-EOS with van der Waals and Zhang-Masuoka mixing rules were optimized.

Reine and Eldridge [25] examined the solubility and absorption of ethylene in $\mathrm{CuCl} /$ Aniline/NMP solvent in an autoclave apparatus. They found that ethylene-ethane equilibrium selectivity was a severe function of total gas phase pressure. Kinetic behavior was justified with acceptable accuracy by an instantaneous reversible mechanism. Also, this solvent had a good stability during experiments.

Charin et al. [6] reported phase equilibrium data at high pressures (up to 160 bar) for the binary and ternary systems formed by propane + NMP + methanol in the temperature range of 363-393 K. The experimental data were modeled using PR-EOS with Wong-Sandler and the classical quadratic mixing rules, affording a satisfactory representation of the experimental data.

Sun et al. [33] examined the effect of temperature and pressure on the solubility of propylene and polypropylene in alcoholic solvents in absorption cell. Also, solubility was modeled using SRK-EOS and Wilson activity coefficient model.

Sato et al. [28] measured the solubility of ethylene in organic solvents (toluene + norbornene) at different temperatures and pressures. After modeling with PR-EOS, solubility data and binary interaction parameters were obtained with great accuracy.

Shariati et al. [30] measured the solubility of ethylene in methyl propionate at pressures up to 107 bar and temperatures from 283 to $464 \mathrm{~K}$. The absolute average deviation of the results of PR-EOS and experimental data were about $5.8 \%$.

Azizi et al. [1] examined propane/propylene absorption in NMP at various temperatures and pressures. 1-parameter and 2-parameters PR-EOS were separately implemented and the binary interaction parameters were adjusted. The prediction of the thermodynamic model had an acceptable accuracy regarding the experimental data.

Cancelas et al. [5] studied solubility and diffusivity of propylene, ethylene and propylene-ethylene mixture in polypropylene at different temperatures and pressures. They used Sanchez-Lacombe EOS to obtain isothermal absorption of both binary systems. For both systems, binary interaction parameters decreased with temperature. They found that at lower temperatures, the sum of pure gas solubilities was less than total solubility of the gas mixture. Also, the effective diffusivity of pure gases was more than ethylene-propylene mixture. 
Kitagishi et al. [15] measured the solubility and diffusivity of ethylene in four propylene-based copolymer (cPP) samples at below and above melting point temperatures of each samples. These values were achieved with cPP crystallinities and free-volume-theory (FVT) parameters that found from molten state data.

The current work presents an in-depth study into the equilibrium and kinetics of absorption of ethylene in NMP at temperature range of $278.15-328.15 \mathrm{~K}$ and pressure up to $14 \mathrm{bar}$. Also, thermodynamic modeling was performed using PR-EOS and Wilson activity coefficient model, while adjusting binary interaction parameters $\Lambda_{12}, \Lambda_{21}$. Finally, the modeling and experimental results were compared and the accuracy of the calculations was determined.

\section{Experimental}

\section{Materials}

Ethylene $\left(\mathrm{C}_{2} \mathrm{H}_{4}\right)$ and NMP $\left(\mathrm{C}_{5} \mathrm{H}_{9} \mathrm{NO}\right)$ were supplied from Amir Kabir Petrochemical Company (AKPC), Mahshahr, Iran. NMP is a colorless liquid with a slight amine odor and is miscible with water. Since NMP has a low vapor pressure at the operating temperatures (e.g., 0.0007 bar at $298.15 \mathrm{~K}$ compared with 0.032 bar for water), and this value is very small in comparison with the operating pressures, its loss and evaporation during the operation seems to be negligible. Indeed, high normal boiling point of NMP $(475.15 \mathrm{~K})$ in comparison with other customarily used solvents enhances its ability to use as solvent. The reason for choosing this solvent was its high solubility and polarity, which enables it to separate olefins from paraffins. One of the most important properties of this solvent is that it solubilizes unsaturated hydrocarbons more than saturated hydrocarbons. All chemicals were used without further purification. Result of chemical analysis of NMP used in this study showed that its water content was about $1 \mathrm{~mol} \%$. The specifications of the materials used in this study are shown in Table 1. The Antoine equation $\left(\log P^{*}(m m H g)=A-\frac{B}{T\left({ }^{\circ} \mathrm{C}\right)+C}\right)$ was used to calculate the vapor pressure of the compounds. The critical properties, the acentric factors, and the constants of Antoine equation for the components of interest in this study are also listed in Table 1.

\section{Apparatus}

The absorption equilibrium and kinetic data were gathered using a stirred equilibrium cell. The experimental set-up used in this study is shown in Fig. 1. It includes a gas storage tank, regulator, middle cell, absorption cell, magnetic stirrer, vacuum pump, water bath, pressure and temperature transmitters, and some indicators.

First of all, the equilibrium cell is filled by a predetermined amount of technical grade solvent. Then, the equilibrium cell, the intermediate cell, and all the connections and tubing were evacuated using a vacuum pump (JB Industries DV-200 N, USA). Ethylene as the feed gas first conducted to the intermediate cell while the connection to the main equilibrium cell was blinded. This cell was a 0.51 stainless steel sampling bomb equipped with a PT-100 $\Omega$ with a maximum pressure tolerance of about 200 bars. After a while, the needle valve connected the equilibrium cell and the intermediate cell was opened and the gas conducted to the equilibrium cell. A sudden pressure drop occurred due to the volume expansion and then a gradual pressure drop occurred according to the absorption process. All the data of the variation of pressure versus time were recorded.

The equilibrium cell which was equipped with a magnetic stirrer, was a 0.371 cell, made up of a 316 stainless steel material and could tolerate a maximum pressure of 25 bars. The speed of magnetic stirrer was set (about $270 \mathrm{rpm}$ ) so that no vortex occurs on the surface of liquid while a complete mixing was ensured. The temperature and pressure of the cell were measured by an RTD sensor (PT-100 $\Omega$ ) with the accuracy of $\pm 0.2 \mathrm{~K}$, and absolute pressure transducer (model PSCH0025BCIJ of Sensys Co.) with the precision of \pm 0.01 bar. To maintain the absorption temperature at a given value, a water bath was implemented. The volume of this water bath is about 61 .

It should be noted that this lab-made set-up can withstand a maximum temperature of $333 \mathrm{~K}$ and a maximum pressure up to 16 bar in the absorption cell. Care should also be taken during the test to ensure that the gas under test remains in the gaseous state. Due to the reasons given and also by studying the research of the others, the temperature range of 278-328 $\mathrm{K}$ and pressure up to $14 \mathrm{bar}$ were determined for experiments. The similar apparatus had previously been used $[1,3,427]$, and the obtained results had been approved by different approaches.
Table 1 The properties of the materials used in this study $[32,36]$

\begin{tabular}{|c|c|c|c|c|c|c|c|c|}
\hline Component & Purity & $T_{c}(K)$ & $P_{c}($ bar $)$ & $\omega$ & $M_{w}\left(\frac{g}{m o l}\right)$ & $A$ & $B$ & $C$ \\
\hline Ethylene & $99.8 \mathrm{~mol} . \%$ & 282 & 50.42 & 0.087 & 28.05 & 6.966 & 649.81 & 262.73 \\
\hline NMP & 99.7 wt. $\%$ & 724 & 47.2 & 0.361 & 99.13 & 7.361 & 1869.62 & 215.29 \\
\hline
\end{tabular}


Fig. 1 Schematic representation of the experimental apparatus

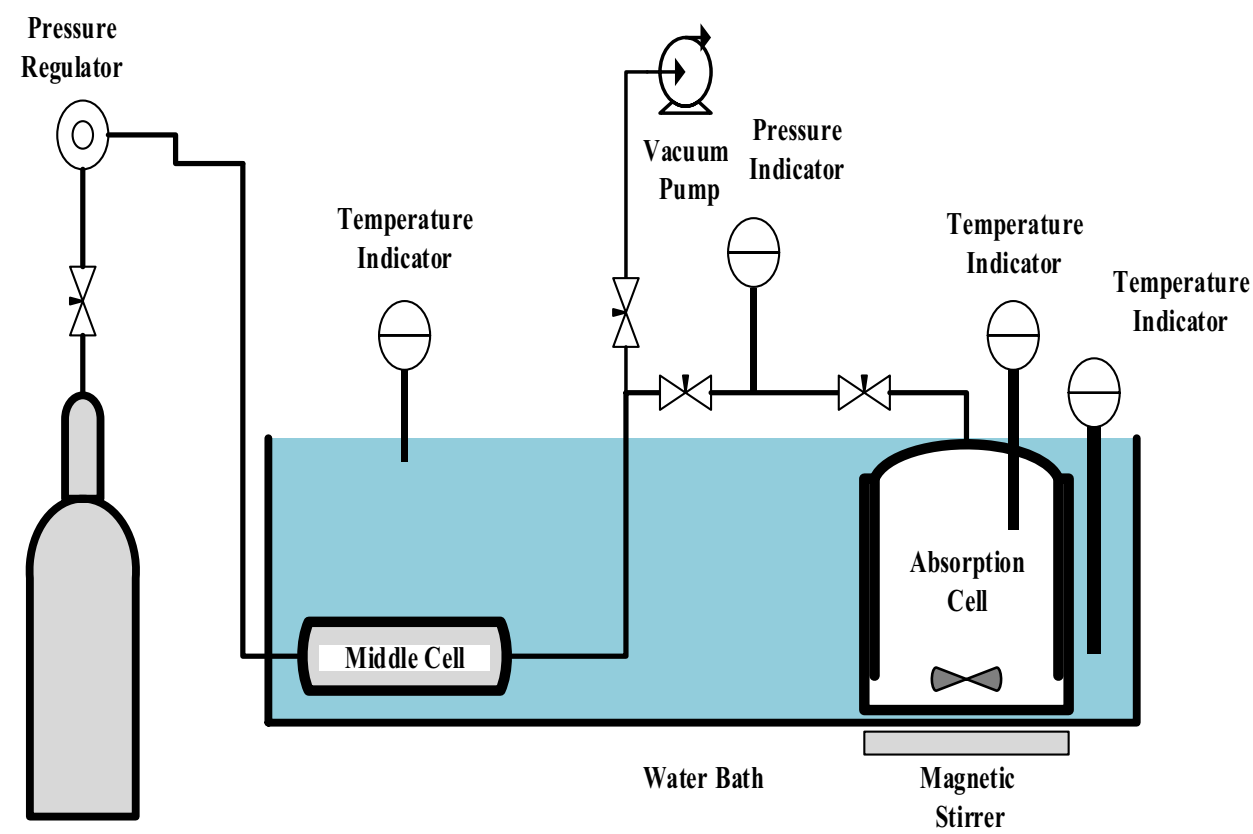

Gas Cylinder

\section{Assumptions and calculations}

The followings are the main assumptions considered in calculating the equilibrium mole fractions:

1) Due to the low volatility of NMP, the amount of solvent in the vapor phase was negligible, therefore, the vapor phase was considered to be pure. It is worth mentioning that if the molar fraction of NMP in the vapor phase is taken into account, the ethylene molar fraction in the vapor phase is changed to $y_{1}=0.9999$ instead of $y_{1}=1$. It results in maximum 5\% variation in solubility values (in the fourth decimal place of solubility). That is, the assumption that the vapor phase is pure is a reasonable assumption. Other researchers also confirmed this assumption in their work [1,4].

2) After the evacuation, the amount of air in the system was neglected.

3) No mass transfer resistance occurred at the gas phase since this phase was considered as a pure substance.

4) No volume change in the liquid phase was considered. As the volume of the gas phase was nearly 8 times greater than that of the liquid phase, the volumetric expansion of liquid which was a portion of liquid volume did not change the volume of gas significantly. Furthermore, the solubility of ethylene in NMP was low enough $(x<0.1)$. This small dissolution of the gas in the solvent does not change the volume of the solvent considerably.
To calculate the number of moles of absorbed gas or solubility in each state, gas volume must first be determined.

$V_{g . f}=V_{t}-V_{s}$

where $V_{s}$ is volume of the initial solvent, $V_{t}$ is total volume and $V_{g, f}$ is the final volume of gas.

Then the absorbed gas moles $\left(n_{g}\right)$ are obtained from the following mass balance from the initial pressure $\left(P_{1}\right)$ to the final pressure (equilibrium state). It should be noted that all the experiments performed at the constant temperature condition.

$n_{g}=\frac{1}{R T}\left[\frac{P_{1} \cdot V_{g, 1}}{Z_{1}}-\frac{P_{e q} \cdot V_{g, f}}{Z_{e q}}\right]$

where $V_{g, 1}$ is the initial volume of gas (intermediate cell volume), $R$ is gas constant (83.14 $\left.\frac{\mathrm{bar.cm}}{\mathrm{mol} . \mathrm{K}}\right)$, T is operating temperature (K), $P_{1}$ is initial pressure (bar), $P_{e q}$ is final pressure (bar), $Z_{1}$ is compressibility factor at initial condition, and $Z_{e q}$ is compressibility factor at equilibrium condition. The compressibility factor was calculated using Peng Robinson EOS [14, 21].

The number of moles of solvent $\left(n_{s}\right)$ was obtained as Eq. (3):

$n_{s}=\frac{\rho_{s} \cdot V_{s}}{M_{s}}$ 
where $\rho_{s}$ is density of the solvent $\left(\frac{g}{\mathrm{~cm}^{3}}\right), V_{s}$ is the solvent volume, and $M_{s}$ is molecular weight of the solvent. The solubility of ethylene in term of their mole fraction is calculated according to Eq. (4):

$x=\frac{n_{g}}{n_{g}+n_{s}}$

\section{Thermodynamic modeling}

The $\Phi-\gamma$ approach was applied to describe the equilibrium criterion as follow [32]:

$y_{1} \phi_{1} P=x_{1} \gamma_{1} P_{1}^{\text {sat }}$

where $y_{1}$ is mole fraction of ethylene in gas phase, $x_{1}$ is mole fraction of ethylene in liquid phase, $\mathrm{P}$ is total pressure (or equilibrium pressure), $\phi_{1}$ is fugacity coefficient of ethylene in gas phase, $\gamma_{1}$ is activity coefficient of ethylene in liquid phase, and $P_{1}^{s a t}$ is saturated pressure of ethylene.

Using Eqs. (6)-(13), the value of $\Phi$ was calculated by PREOS $[14,21]$. It should be noted that according to the assumptions mentioned above, the gas phase can be assumed to be pure $\left(y_{1}=1\right)$, because the solvent volatility is negligible [1].

$\ln \phi=Z-1-\ln (Z-B)-\frac{A}{2 \sqrt{2} B} \ln \left(\frac{Z+2.414 B}{Z-0.414 B}\right)$

where $Z$ should be calculated using PR-EOS as follows:

$Z^{3}-(1-B) Z^{2}+\left(A-2 B-3 B^{2}\right) Z-\left(A B-B^{2}-B^{3}\right)=0$

The terms A and B were calculated as follows:

$$
\begin{aligned}
& A=\frac{a P}{R^{2} T^{2}} \\
& B=\frac{b P}{R T} \\
& b=0.077796 \frac{R T_{c}}{P_{c}} \\
& m=0.37464+1.54226 \omega-0.26992 \omega^{2} \\
& \alpha=\left[1+m\left(1-T_{r}^{0.5}\right)\right]^{2} \\
& a=0.457235 \frac{R^{2} T_{c}^{2}}{P_{c}} \alpha
\end{aligned}
$$

where $T_{c}$ is critical temperature $(\mathrm{K}), P_{c}$ is critical pressure (bar), $\omega$ is acentric factor, $T_{r}$ is reduced temperature, $\phi$ is fugacity coefficient, and $\mathrm{Z}$ is compressibility factor.

In this work, the parameter of $\gamma$ was calculated using Wilson activity equation which is represented in Eq. (14). The two binary interaction parameters $\Lambda_{12}$ and $\Lambda_{21}$ are included in Eq. (14) [13, 33]. These parameters are a function of temperature and always are greater than zero [32]. Based on Wilson equation, $\gamma$ is a function of liquid mole fraction and temperature.

$\ln \gamma_{i}=-\ln \left(x_{i}+x_{j} \Lambda_{i j}\right)+x_{j}\left(\frac{\Lambda_{i j}}{x_{i}+x_{j} \Lambda_{i j}}-\frac{\Lambda_{j i}}{x_{j}+x_{i} \Lambda_{j i}}\right)$

The algorithm to calculate the liquid mole fraction and optimizing the binary interaction parameters from experimental data is shown in Fig. 2.

Based on this flowchart, the binary interaction parameters were adjusted so that the error of model be minimized. The required data and required constants were given as input. Then, a set of binary interaction parameters was selected. By selecting any experimental pressure, flash calculations were performed according to the $\Phi-\gamma$ method. Accordingly, the value of $x_{\text {model }}$ was obtained. When the values of $\mathrm{x}$ were calculated by each set of binary interaction parameters and all pressures at constant temperature, then the absolute average deviation (AAD) with respect to solubility was calculated until the binary interaction parameters $\left(\Lambda_{12}, \Lambda_{21}\right)$ were optimized.

$\% A A D=\frac{100}{N} \sum_{i=1}^{N} \frac{\left|x_{\text {exp }}-x_{\text {mod }}\right|}{x_{\text {exp }}}$

where $x_{\text {exp }}$ is a experimental mole fraction, and $x_{\text {mod }}$ is calculated mole fraction.

\section{Results and discussion}

\section{Kinetics of absorption}

The variations of pressure with time for the absorption of ethylene gas in $100 \mathrm{ml}$ NMP solvent at $298.15 \mathrm{~K}$ and various initial pressures were illustrated in Fig. 3. Similar graphs were obtained for other temperatures which were not shown here. Also, $\mathrm{P}-\mathrm{t}$ graph at same initial pressure $(\approx 6$ bars $)$ and various temperatures are shown in Fig. 4. Similar graphs were drawn for other initial pressures (about 2.3, 4, 6, 8, 11, and 14 bar) and different temperatures. The duration of these experiments lasted from 80 to $260 \mathrm{~min}$.

It should be mentioned that pressure decay continues until the solvent gets saturated with the gas, then the pressure does not change with time and the final pressure is reached which 


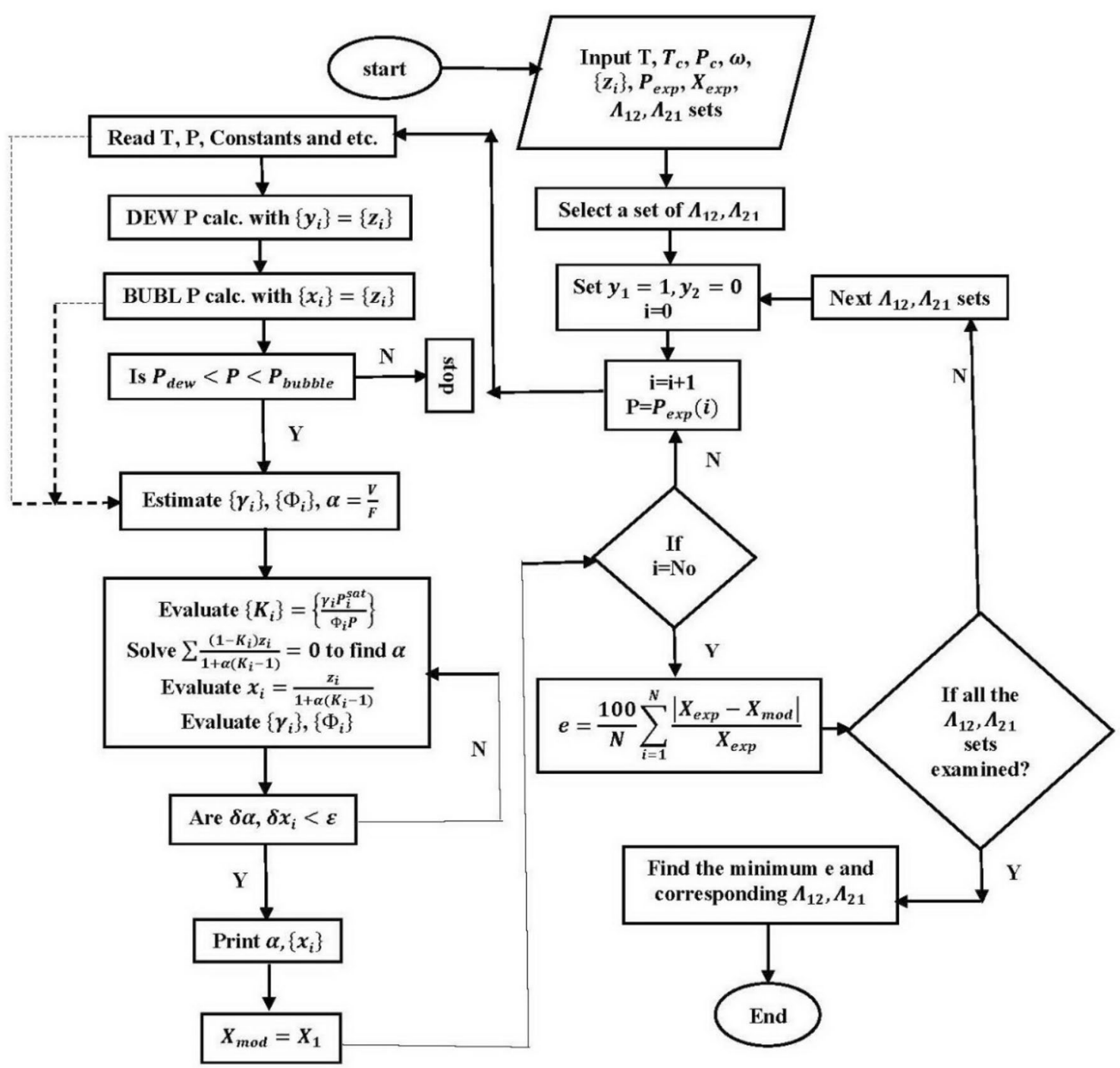

Fig. 2 The algorithm used to calculate the solubility of ethylene in NMP based on PR-EOS and Wilson activity coefficient model

is the equilibrium pressure. It is assumed that when the pressure change is not observed for about $20 \mathrm{~min}$, the equilibrium condition is reached. Figure 3 demonstrates that pressure decay was greater during the absorption at higher initial pressures. Furthermore, according to kinetic results, faster absorption occurred at higher temperatures. Figure 4 shows that at constant operating pressure, more time was needed to reach the equilibrium at lower temperature. Because molecules are absorbed more slowly due to the lower movement and activity at low temperature. The higher the temperature, the higher the absorption rate.

In this study, a constant stirrer speed was considered which was $270 \mathrm{rpm}$. If stirrer speed is lower, it will take longer to reach the equilibrium. As the speed of the stirrer increases, the rate of attaining the equilibrium will increase. At the same time, it should be noted that the maximum stirrer speed should be selected in such a way that no vortex flow created inside the solvent. The presence of the vortex flow causes the solvent to deviate from the well-mixed state, therefore, the accuracy of solubility data may be influenced. Since the main purpose and focus of this paper is to investigate the equilibrium and solubility of gases in solvent, stirrer speed has not been studied. The results of Figs. 3 and 4 are provided only to check the temperature and pressure effects on the kinetic behavior. It is important to note that if the stirrer speed is selected at the appropriate range, its value cannot affect the absorption equilibrium data, which is the main purpose of this paper.

\section{Absorption equilibrium}

The equilibrium mole fraction of ethylene gas in solvent was obtained using Eq. (4). The equilibrium data of ethylene at different temperatures are presented in Fig. 5. In this Figure, 


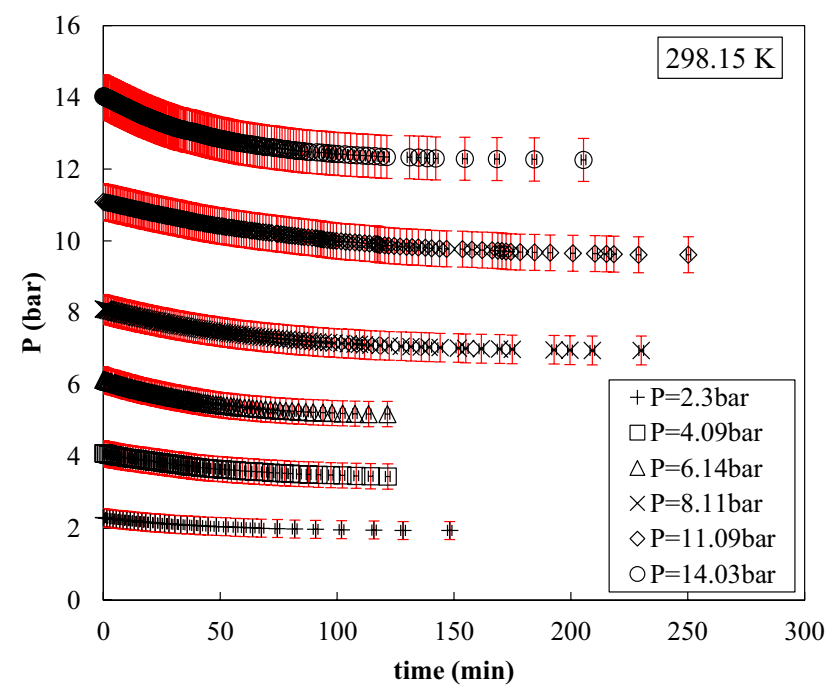

Fig. 3 Time dependence of the absorption of ethylene in NMP at $298.15 \mathrm{~K}$ and different initial pressures

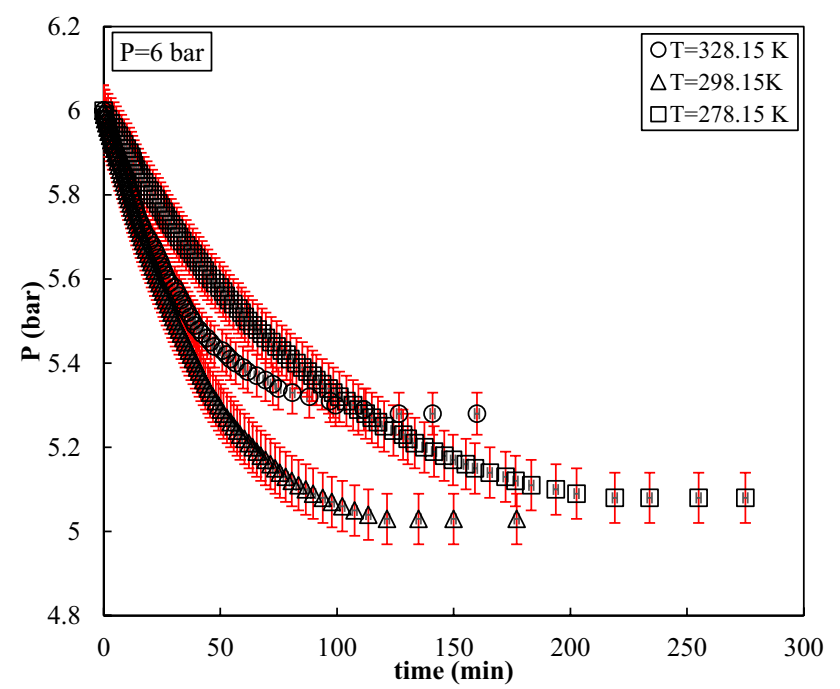

Fig. 4 Time dependence of the absorption of ethylene in NMP at about 6 bar and various temperatures

the equilibrium solubility of the experimental results and the modeling results were presented. As can be seen, increase of temperature reduces the gas solubility. At higher pressures, the effect of temperature on the solubility of ethylene is more noticeable.

Assuming the linearity of pressure variations in terms of solubility, the slope of this line is Henry's law constant. Eq. (16) correlates the equilibrium pressure with the solubility of dilute solutions:

$P_{e q}=H \times x$

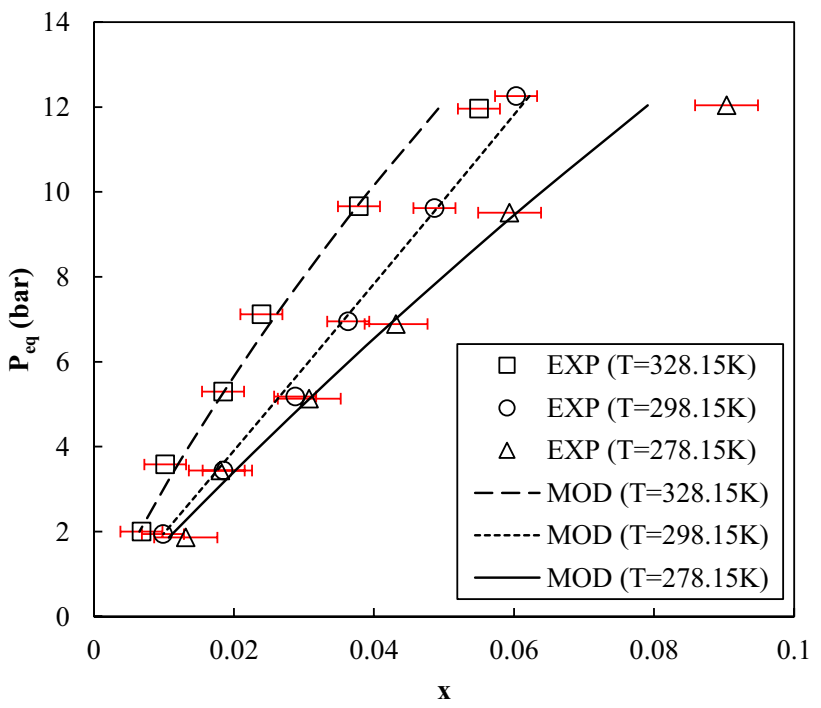

Fig. 5 The equilibrium data and the model prediction for the absorption of ethylene in NMP at different temperatures

Table 2 Henry's law constants and the constants of Arrhenius equation for ethylene absorption in NMP/water system

\begin{tabular}{|c|c|c|c|c|c|}
\hline$T(\mathrm{~K})$ & $\begin{array}{l}x_{\mathrm{w}}(\text { water } \\
\text { mole frac- } \\
\text { tion) }\end{array}$ & $H$ (bar) & $H_{0}($ bar $)$ & $\Delta H=-E\left(\frac{k J}{m o l}\right)$ & Ref \\
\hline 278.15 & 0.011 & 146.31 & 4046.2 & -7.61 & This work \\
\hline 298.15 & & 196.93 & & & \\
\hline 328.15 & & 243.05 & & & \\
\hline \multirow[t]{4}{*}{298.15} & 0 & 135.6 & - & - & [38] \\
\hline & 0.083 & 159.6 & & & \\
\hline & 0.194 & 202.7 & & & \\
\hline & 0.277 & 248.2 & & & \\
\hline 298.15 & 0 & 127.64 & - & - & [26] \\
\hline 298.15 & 0 & 136.76 & 3640.9 & -8.14 & [29] \\
\hline 323.15 & 0 & 176.30 & & & \\
\hline 343.15 & 0 & 210.70 & & & \\
\hline 273.15 & 0 & 98.9 & 5014.1 & -8.8 & [11] \\
\hline 278.15 & 0 & 108.6 & & & \\
\hline 283.15 & 0 & 117.31 & & & \\
\hline 288.15 & 0 & 128.3 & & & \\
\hline \multirow[t]{3}{*}{278.15} & 0.104 & 135.34 & - & - & [11] \\
\hline & 0.241 & 178.6 & & & \\
\hline & 0.378 & 298.53 & & & \\
\hline \multirow[t]{3}{*}{293.15} & 0.104 & 161.3 & - & - & \\
\hline & 0.241 & 209.5 & & & \\
\hline & 0.378 & 349.2 & & & \\
\hline
\end{tabular}

where $\mathrm{H}$ is Henry's law constant. The values of Henry's law constants at different temperatures were reported in Table 2. The Henry's law constant is related to temperature as an Arrhenius type model as follows: 


$$
H=H_{0} \exp \left(\frac{-E}{R T}\right)
$$

As can be seen in Fig. 6, when the values of $\ln \mathrm{H}$ are plotted in terms of the inverse of temperature, the constants of Arrhenius type equation would be obtained. These constants are used to correlate the solubility data of ethylene in NMP. These data are also shown in Table 2. The activation energy indicates the dependence of absorption on the temperature. Higher activation energy shows that the absorptivity of the solvent has strong variations with temperature. As shown

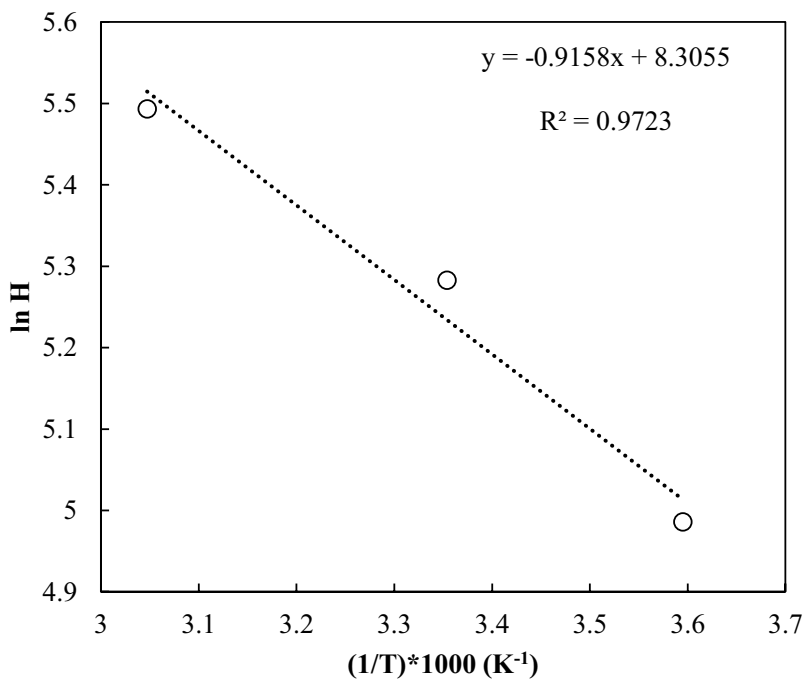

Fig. 6 The Arrhenius type model to calculate Henry's law constant as a function of temperature in Table 2, the enthalpy of ethylene absorption in NMP is $7.61 \mathrm{~kJ} / \mathrm{mol}$. As Svensson et al. [34] stated, the absorption enthalpy up to the range of $14-16 \frac{\mathrm{kJ}}{\mathrm{mol}}$ is indicative for physical absorption. It means that the absorption of ethylene in NMP is inherently physical, and minor energy exchange is occurred during the absorption.

The calculated Henry's law constants and also the constants of Arrhenius equation for ethylene/NMP/water system were compared with the scarce previous works in Table 2. Table 2 shows that the values of Henry's law constants are close to those reported in the previous works.

Although in this work the water content of NMP is constant $\left(x_{\mathrm{w}}=0.011\right)$, it is clear from the previous works [11, $38]$ that the higher water content increases the Henry's law constant and therefore, decreases the solubility of ethylene in NMP/water mixture.

\section{Thermodynamic modeling results}

The results of thermodynamic modeling and optimal binary interaction parameters were presented in Table 3. As it turned out, the \%AAD is about $3.5-7.7 \%$.

Figure 7 compares the calculated solubility of ethylene in NMP using PR-EOS and Wilson activity coefficient model at different temperatures with the experimental data. It is obvious that very good agreement was obtained. As expected, due to the large difference in the chemical nature of solute and solvent, a positive deviation from the ideal law was observed $(\gamma>1)$. This means that the interaction forces of the similar molecules are greater than those of non-identical molecules.
Table 3 Comparison of the experimental data and the modeling results including optimized values of the binary interaction parameters in Wilson activity equation

\begin{tabular}{lllllll}
\hline$T(\mathrm{~K})$ & $P_{\text {eq }}($ bar $)$ & $x_{\text {exp }}$ & $x_{\text {mod }}$ & $\Lambda_{12}$ & $\Lambda_{21}$ & \% AAD \\
\hline 328.15 & 11.96 & 0.0550 & 0.0492 & 0.15 & 1.83 & 7.2437 \\
& 9.66 & 0.0378 & 0.0376 & & & \\
& 7.12 & 0.0239 & 0.0261 & & & \\
& 5.3 & 0.0185 & 0.0186 & & & \\
& 3.58 & 0.0102 & 0.012 & & & \\
& 2 & 0.0068 & 0.0065 & & & 3.4876 \\
& 12.26 & 0.0603 & 0.0622 & 0.84 & 0.12 & \\
& 9.62 & 0.0486 & 0.049 & & & \\
& 6.95 & 0.0363 & 0.0355 & & & \\
& 5.18 & 0.0288 & 0.0265 & & & \\
& 3.44 & 0.0185 & 0.0176 & & & \\
& 1.94 & 0.0099 & 0.0099 & & & \\
& 12.04 & 0.0904 & 0.0791 & 0.42 & 0.52 & \\
& 9.51 & 0.0594 & 0.0604 & & & \\
& 6.89 & 0.0432 & 0.0423 & & & \\
& 5.13 & 0.0307 & 0.0308 & & & \\
& 3.44 & 0.0181 & 0.0202 & & & \\
& 1.86 & 0.0131 & 0.0107 & & & \\
\end{tabular}




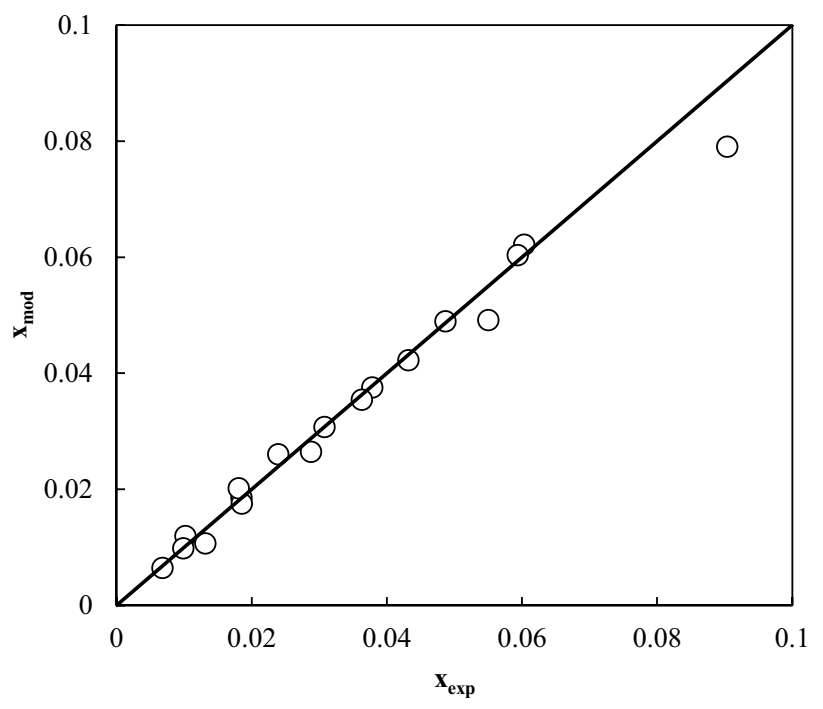

Fig. 7 Calculated ethylene solubility in NMP using PR-EOS and Wilson equation

For a quantitative description of high pressure phase equilibria ( $P>10$ bar) equations of state and for low pressure phase equilibria $(P<10$ bar $)$ models based on the activity coefficient are useful [23, 24, 32]. Because in this research, the activity coefficient model has been used, in Figs. 5 and 7 , the higher the pressure (the higher the mole fraction), the greater the deviation between the model predictions and the experimental values.

Figure 8 illustrates the sensitivity of the thermodynamic model on the variation of binary interaction parameters of Wilson activity coefficient model. In this figure, the values of the resulting A.A.D. were plotted in relation to the different values of the binary interaction parameters at 278.15, 298.15 and 328.15 K. It should be mentioned that in Fig. 8, only the values representing the error below $100 \%$ for $328.15 \mathrm{~K}$, and $30 \%$ for 298.15 and $35 \%$ for $278.15 \mathrm{~K}$ were illustrated for the sake of clarity.

The minimum regions of these curves show the optimal range of the binary interaction parameters which were previously reported in Table 3. According to the calculations, by neglecting the binary interaction parameters in the model $\left(\Lambda_{i j}=0\right)$, about $100 \%$ error was obtained. This highlights the importance of these parameters in computing, especially in commercial software.

\section{Conclusion}

- Ethylene absorption has been performed in a batch stirred vessel using NMP as solvent at the temperatures of $278.15,298.15$, and $328.15 \mathrm{~K}$, and pressures of up to 14 bar. Then, PR-EOS and Wilson activity coefficient
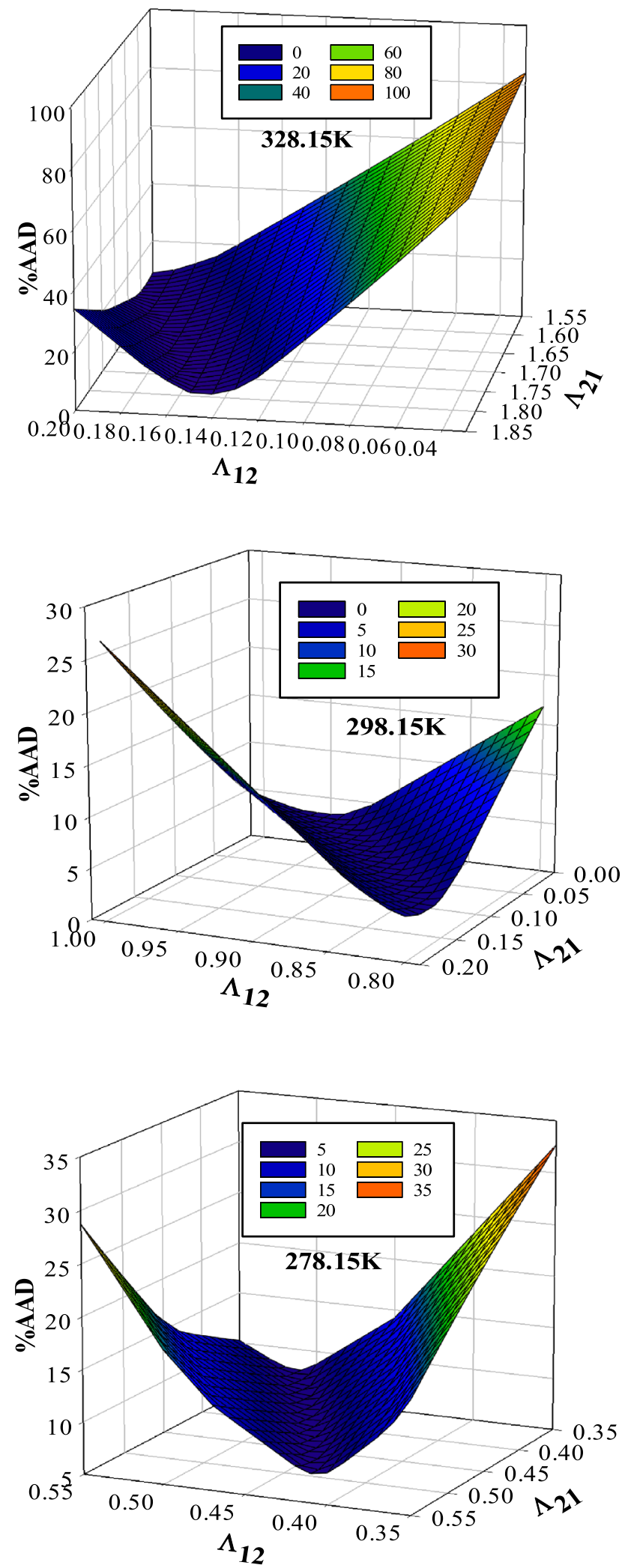

Fig. 8 The effect of binary interaction parameters on the correlation of solubility data of ethylene in NMP at different temperatures 
model was implemented to correlate the solubility of ethylene in NMP using $\Phi-\gamma$ approach. The following important conclusions were obtained:

- Absorption was faster at higher temperatures.

- Higher pressure and lower temperature were desirable condition for solubility of ethylene in NMP.

- The Arrhenius type model was compatible with the experimental data for Henry's law constant calculation to show its dependence on temperature.

- The optimized values of $\Lambda_{12}, \Lambda_{21}$ in Wilson activity coefficient model were calculated using a trial and errorbased algorithm.

- Experimental data and thermodynamic modeling results had an acceptable agreement (less than 7.7\% deviation) when the appropriate values of the binary interaction parameters were used.

Acknowledgment This paper was prepared from a Ph.D. thesis conducted in the Department of chemical Engineering, Mahshahr branch, Islamic Azad University, Mahshahr, Iran.

Open Access This article is licensed under a Creative Commons Attribution 4.0 International License, which permits use, sharing, adaptation, distribution and reproduction in any medium or format, as long as you give appropriate credit to the original author(s) and the source, provide a link to the Creative Commons licence, and indicate if changes were made. The images or other third party material in this article are included in the article's Creative Commons licence, unless indicated otherwise in a credit line to the material. If material is not included in the article's Creative Commons licence and your intended use is not permitted by statutory regulation or exceeds the permitted use, you will need to obtain permission directly from the copyright holder. To view a copy of this licence, visit http://creativecommons.org/licenses/by/4.0/.

\section{References}

1. Azizi S, Dezfuli HT, Kargari A, Peyghambarzadeh SM (2015) Experimental measurement and thermodynamic modeling of propylene and propane solubility in N-methyl pyrrolidone (NMP). Fluid Phase Equilib 387:190-197

2. Bao Z, Chang G, Xing H, Krishna R, Ren Q, Chen B (2016) Potential of microporous metal-organic frameworks for separation of hydrocarbon mixtures. Energy Environ Sci 9:3612-3641

3. Bohloul M, Sadeghabadi MA, Peyghambarzadeh SM, Dehghani $\mathrm{M}$ (2017) $\mathrm{CO}_{2}$ absorption using aqueous solution of potassium carbonate: experimental measurement and thermodynamic modeling. Fluid Phase Equilib 447:132-141

4. Bohloul M, Vatani A, Peyghambarzadeh SM (2014) Experimental and theoretical study of $\mathrm{CO}_{2}$ solubility in $\mathrm{N}$-methyl-2-pyrrolidone (NMP). Fluid Phase Equilib 365:106-111

5. Cancelas AJ, Plata MA, Bashir MA, Bartke M, Monteil V, McKenna TF (2018) Solubility and diffusivity of propylene, ethylene, and propylene-ethylene mixtures in polypropylene. Macromol Chem Phys 219:1700565

6. Charin RM, Corazza ML, Ndiaye PM, Mazutti MA, Oliveira JV (2010) Phase equilibrium data and thermodynamic modeling of the system propane+ NMP+ methanol at high pressures. J Supercrit Fluids 55:23-31

7. Chmelař J, Smolná K, Haškovcová K, Podivinská M, Maršálek J, Kosek J (2015) Equilibrium sorption of ethylene in polyethylene: Experimental study and PC-SAFT simulations. Polymer 59:270-277

8. Cho IH, Yasuda HK, Marrero TR (1995) Solubility of ethylene in aqueous silver nitrate. J Chem Eng Data 40:107-111. https://doi. org/10.1021/je00017a024

9. DojčanskýJ-Surový JSB (2001) Application of the wilson equation with binary parameters to the prediction of the isothermal vapour-liquid equilibrium data of ternary and quaternary systems in the assessment of the polar solvent in extractive distillation. Chem Pap 55:71-74

10. Eldridge RB (1993) Olefin/paraffin separation technology: a review. Ind Eng Chem Res 32:2208-2212

11. Hayduk W, Battino R, Clever H, Derrick M, Fogg P, Young C (1994) IUPAC solubility data series, vol 57. Oxford University Press, England, Ethene

12. Henni A, Lal D, Mather AE (1996) The solubility of ethane in n-methylpyrrolidinone. Can J Chem Eng 74:423-425

13. Hristova M, Donchev T, Kolev D, Baloch I, Georgiev H (2015) Parameter's estimate in Wilson equation. Int Electro J Pure Appl Math 9:2-35

14. Jaubert J-N, Mutelet F (2004) VLE predictions with the PengRobinson equation of state and temperature dependent kij calculated through a group contribution method. Fluid Phase Equilib 224:285-304

15. Kitagishi A, Takizawa S, Sato Y, Inomata H (2019) Measurement and prediction of solubilities and diffusion coefficients of ethylene in rubbery propylene copolymers. Fluid Phase Equilib 492:110-117

16. Lamia N, Jorge M, Granato MA, Paz FAA, Chevreau H, Rodrigues AE (2009) Adsorption of propane, propylene and isobutane on a metal-organic framework: molecular simulation and experiment. Chem Eng Sci 64:3246-3259

17. Lee L-s, Ou H-j, Hsu H-l (2005) The experiments and correlations of the solubility of ethylene in toluene solvent. Fluid Phase Equilib 231:221-230

18. Manteghian M, Safavi SMM, Mohammadi A (2013) The equilibrium conditions, hydrate formation and dissociation rate and storage capacity of ethylene hydrate in presence of 1,4-dioxane. Chem Eng J 217:379-384

19. Mortaheb H, Mafi M, Mokhtarani B, Sharifi A, Mirzaei M, Khodapanah N, Ghaemmaghami F (2010) Experimental kinetic analysis of ethylene absorption in ionic liquid [Bmim] $\mathrm{NO}_{3}$ with dissolved $\mathrm{AgNO}_{3}$ by a semi-continuous process. Chem Eng J 158:384-392

20. Moura L, Darwich W, Santini CC, Gomes MFC (2015) Imidazolium-based ionic liquids with cyano groups for the selective absorption of ethane and ethylene. Chem Eng J 280:755-762

21. Oba S, Suzuki S, Tanaka H, Nagahama K, Hirata M (1985) Generalization of binary interaction parameters of the pengrobinson equation of state; binary systems containing methane and n-paraffins. J Jpn Petrol Inst 28:202-209

22. Pan Y et al (2016) Separation of methane/ethylene gas mixtures efficiently by using ZIF-67/water-ethylene glycol slurry. Fluid Phase Equilib 414:14-22

23. Poling BE, Prausnitz JM, O'connell JP (2001) The properties of gases and liquids, 5th edn. Mcgraw-Hill, New York

24. Prausnitz JM, Lichtenthaler RN, Azevedo EG (1998) Molecular thermodynamics of fluid phase equilibria, 3rd edn. Prentice Hall PTR

25. Reine TA, Eldridge RB (2005) Absorption equilibrium and kinetics for ethylene-ethane separation with a novel solvent. Ind Eng Chem Res 44:7505-7510 
26. Renon H, Lenoir JY, Renault P (1971) Gas chromatographic determination of Henry's constants of 12 gases in 19 solvents. J Chem Eng Data 16:340-342

27. Roeentan H, Azizi S, Bakeri G, Peyghambarzadeh SM (2017) Experimental measurement of propane and propylene absorption in NMP/AgNO 3 solvent. Chem Eng Res Des 117:240-249

28. Sato Y, Hosaka N, Inomata H, Kanaka K (2013) Solubility of ethylene in toluene, norbornene, and toluene+ norbornene mixture. Fluid Phase Equilib 344:112-116

29. Shakhova S, Zubchenko YP, Kaplan L (1973) Rastvorimost' azota i vodoroda $\mathrm{v}$ organicheskikh rastvoritelyakh Khim Prom (The Soviet Chemical Industry) 49:108-110

30. Shariati A, Florusse LJ, Peters CJ (2015) Solubility of ethylene in methyl propionate. Fluid Phase Equilib 387:143-145

31. Shi M, Lin CC, Kuznicki TM, Hashisho Z, Kuznicki SM (2010) Separation of a binary mixture of ethylene and ethane by adsorption on Na-ETS-10. Chem Eng Sci 65:3494-3498

32. Smith JM, Van Ness HC, Abbott MM (2005) Introduction to chemical engineering thermodynamics, 7 th edn. Mc-GrawHill, Boston

33. Sun Q, Ma X, Guo X, Zhang J (2013) Separation of polypropylene exhaust gas by alcohol absorption method. Fluid Phase Equilib 346:1-7
34. Svensson H, Hulteberg C, Karlsson HT (2013) Heat of absorption of $\mathrm{CO}_{2}$ in aqueous solutions of $\mathrm{N}$-methyldiethanolamine and piperazine. Int J Greenhouse Gas Control 17:89-98

35. Wang Y, Hu Z, Cheng Y, Zhao D (2017) Silver-decorated hafnium metal-organic framework for ethylene/ethane separation. Ind Eng Chem Res 56:4508-4516

36. Washburn EW (2003) International critical tables of numerical data, physics chemistry and technology. knovel, New York

37. Worrell E, Phylipsen D, Einstein D, Martin N (2000) Energy use and energy intensity of the US chemical industry. Lawrence Berkeley National Lab, CA (US)

38. Wu Z, Zeck S, Knapp H (1985) Measurements of the solubility of carbon dioxide, ethylene and methane in $\mathrm{N}$-methylpyrrolidone and in its aqueous solution berichte der bunsengesellschaft für physikalische. Chemie 89:1009-1013

Publisher's Note Springer Nature remains neutral with regard to jurisdictional claims in published maps and institutional affiliations. 